\title{
Joint suits aim to weed out agencies' red tape
}

Helen Pearson, New York

Frustrated with the slow pace of research into medicinal marijuana, researchers have launched a pair of lawsuits accusing US government agencies of obstructing attempts to obtain supplies of the plant.

In order to study marijuana for its ability to ease pain, nausea or symptoms of AIDS, US researchers procure the drug from a small farm at the University of Mississippi, under contract from the National Institute on Drug Abuse (NIDA). But some complain that the red tape and long delays involved in getting the plant through NIDA, the Drug Enforcement Administration (DEA) and other agencies are unacceptable.

The lawsuits, filed on 22 July, were coordinated by the Florida-based campaign group Multidisciplinary Association for Psychedelic Studies (MAPS).

In one lawsuit, MAPS is demanding a decision on an application filed in 2003 to buy 10 grams of NIDA marijuana - a tiny amount worth just $\$ 70$, the group says. The researchers plan to use the plant in testing a vaporizer, an alternative method of delivery to smoking. The test would look at the chemical constituents of the vapour and would not involve human subjects.

The second lawsuit contends that the DEA has stalled an application to set up a separate farm to grow marijuana for research, filed in June 2001 by botanist Lyle Craker of the University of Massachusetts at Amherst. If successful, this would be

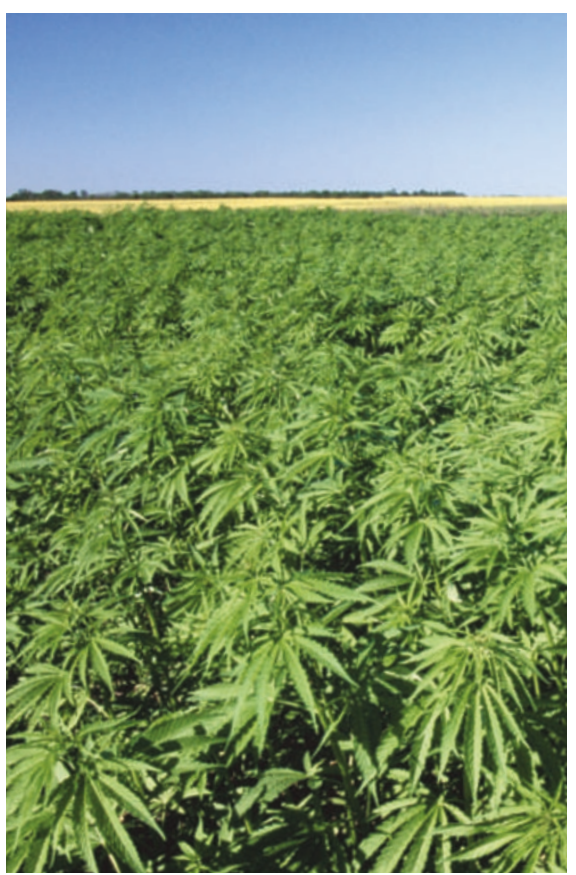

Strong blow: federal agencies are being sued for hampering researchers' access to marijuana.

the first official alternative US marijuana source for medical researchers.

MAPS president Rick Doblin argues that the NIDA supply of marijuana is of low quality and potency, and that researchers will be unable to get clinical approval for drugs derived from it unless they can grow a pharmaceutical-grade crop themselves. He would like to see a situation like that in Britain, where Salisbury-based GW Pharmaceuticals, under licence from the Home Office, has established its own greenhouse facility to grow marijuana for clinical trials.

The US Department of Health and Human Services, NIDA and the DEA would not comment on the lawsuits. But those behind the legal action claim that the agencies are sitting on the applications because they go against the federal government's hard line on drugs. "It's politically unacceptable to say yes," says Craker (see Nature 430, 394-395;2004).

Other researchers in the field agree that the bureaucratic application process for marijuana studies has contributed to sluggishness in the field. "The pace has been slower than one would like," says mental-health researcher Stanley Watson of the University of Michigan, Ann Arbor, who co-authored a 1999 Institute of Medicine report urging clinical trials into medicinal marijuana.

But that does not mean that NIDA is doing anything illegal, Watson says. The agency's remit is to study research linked to the abuse of drugs, he points out, not their medicinal use. "It's going to be a tough one for MAPS to win," says Watson. Others add that there could be scientific problems with the MAPS applications that are holding things up.

Watson suggests that researchers might best forge ahead by improving the design of their trials, or perhaps by negotiating marijuana supplies from other countries.

\section{Sea snapshots will map frequency of freak waves}

Michael Hopkin, London

They are known as 'rogue waves' - the towering walls of water that, some experts suspect, sink tens of ships every year. Now oceanographers are planning to use satellite images to produce a global map of where and how often the rogues occur.

The WaveAtlas initiative follows a trial using three weeks' worth of radar images obtained by the European Space Agency (ESA) from its two European Remote Sensing (ERS) satellites. The trial data covered February and March 2001, a period during which two tourist liners, the Bremen and the Caledonian, had their windows smashed by 30 -metre waves in separate incidents in the Southern Ocean.

The trial's results make hair-raising reading. Besides the two 30-metre giants, the team identified at least eight other waves topping 25 metres across the world. It is a wake-up call for anyone who views rogue waves as a nautical myth, says project member Wolfgang Rosenthal of the GKSS Research Centre in Geesthacht, Germany.

The full project, which will encompass two years' worth of images from 1998 to 2000 , could help to explain the staggering number of unexplained sinkings worldwide. "There are many more accidents than you would think - around two a week," says Rosenthal. "They simply get put down to bad weather."

As the ERS satellites circle the globe, they each take a representative radar snapshot of an area 10 kilometres by 5 kilometres for every 200 kilometres of the Earth's surface they cover. The WaveAtlas team uses the amount of radar reflected to determine the incline of the ocean surface, and therefore the size of the waves captured in the image. The researchers have received $75 \%$ of the requested images from ESA, and hope to complete the analysis early next year.

Project leader Susanne Lehner, a marine physicist at the University of Miami, Florida,

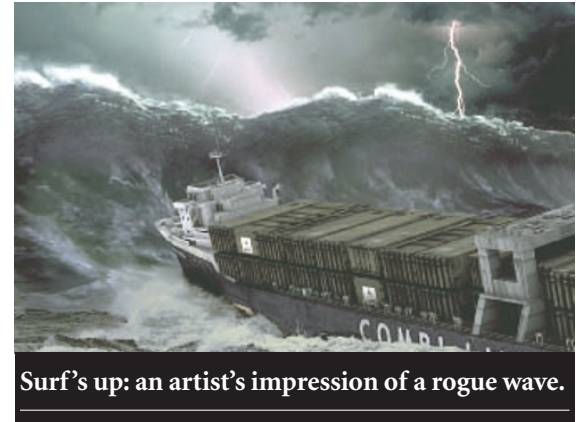

suspects that rogue waves can form when existing waves are chased by a storm system moving at roughly the same speed. "We want to see what weather patterns they are associated with," she says.

The project could also inform the design of ships and oil platforms, Rosenthal argues. Most current platforms are built with a clearance of 15 metres, he says. "The designers think they did a good job, but officers on the platform say 'we get wet feet'.” 